\title{
Who can wait for the future? A personality perspective
}

Vaishali Mahalingam, University of Cambridge:

Vaishali Mahalingam's doctoral research focuses on individual differences in delay discounting and how this relates to subjective perception of one's probability of survival.

Dr. David Stillwell, University of Cambridge:

While researching for his $\mathrm{PhD}$ in cognitive decision-making, David created a Facebook application called myPersonality that provides real psychological questionnaires and gives users feedback on their results. More than 6 million individuals have taken a questionnaire. As a Research Associate at the Psychometrics Centre, he currently collaborates with researchers in different disciplines to mine the myPersonality database for interesting research findings. Michal Kosinski, University of Cambridge:

Michal is Director of Operations and PhD candidate at The Psychometrics Centre. Michal's research (sponsored by Boeing) focuses on the online environment and encompasses the relationship between psychological traits and online behaviour, crowd-sourcing platforms, auctioning platforms, and online psychometrics.

Prof. John Rust, University of Cambridge:

John is Director of The Psychometrics Centre and Director of Research in the Department of Psychology. John combines a huge academic and intellectual reputation in the field of testing and assessment with practical applications experience in a range of blue chips. His work ranges from the investigation of advanced statistical and computational techniques for use in test development, to the UK standardisations of widely used psychometric tests. 
Dr. Aleksandr Kogan, University of Cambridge:

Aleksandr Kogan is a Lecturer in Psychology in the Department of Psychology. Dr. Kogan's research has centered on exploring prosocial emotional processes, including positive emotions and selflessness, across a variety of intra- and interpersonal contexts. Dr. Kogan uses a diverse set of methodological approaches across psychological, behavioral, genetic, and physiological levels of analysis, employ a multitude of paradigms (dyadic interactions, daily experience, psychophysiological recording, experimental, and thin-slicing), and distinct cultural groups.

Words: 4931

Figures: 1

Tables: 2

References: 56

Appendices: 3

Corresponding Author:

Vaishali Mahalingam, The Psychometrics Centre Department of Psychology University of Cambridge Downing Street, Cambridge CB2 3EB.

Email: vm298@cam.ac.uk 


\begin{abstract}
Who can wait for larger, delayed rewards rather than smaller, immediate ones? Delay discounting measures the rate at which subjective value of an outcome decreases as the length of time to obtaining it increases. Previous work has shown that greater delay discounting predicts negative academic, social, and health outcomes. Yet little is known about who is likely to engage in greater or less delay discounting. Taking a personality perspective, in a large sample $(N=$ 5888), we found that greater delay discounting was predicted by low Openness and Conscientiousness, and higher Extraversion and Neuroticism. Smaller amounts were also discounted more than larger amounts; furthermore, amount magnified the effects of Openness and Neuroticism on delay discounting. Our findings show that personality is one predictor of individual differences in delay discounting — an important implication for intervention approaches targeted at delay discounting.

Key words: Decision Making, Individual Differences, Hierarchical Linear Modeling/Multilevel Modeling, Personality, Social Network, Delay Discounting
\end{abstract}


People do not like to wait; thus, more distant rewards - that people have to wait forhave less subjective value than immediate rewards. Delay discounting is the rate at which the subjective value of a reward decreases as the length of time (delay) before it is obtained increases. For example, would you rather have $\$ 90$ now or $\$ 100$ in a year? $\$ 50$ now or $\$ 100$ in a year? A higher rate of discounting implies that one is 'impatient' and prefers smaller immediate rewards rather than waiting for larger rewards at a later time. Such a preference has been associated with a range of addictive and impulsive behaviors, including smoking (Krishnan-Sarin et al., 2007; Reynolds et al., 2007), drug use (Kirby \& Petry, 2004) and obesity (Weller et al., 2008). In contrast, lower rates of discounting - having a preference for larger rewards in the future - have been linked to better academic performance and social functioning, such as social relationships and self-control behavior (Kirby, Winston, \& Santiesteban, 2005; Mischel, Shoda, \& Rodriguez, 1989).

One important mechanism that determines the degree to which people engage in delay discounting is the reward size — the 'magnitude effect'. While some have suggested that degree of delay discounting is a constant trait (Odum, 2011), experimental evidence shows that rate of discounting varies as a function of amount (Lane et al., 2003). Most studies that tested the magnitude effect found individuals discount smaller rewards more steeply than larger ones (Green, Fristoe, \& Myerson, 1994; Green, Fry, \& Myerson, 1994; Kirby, 1997; Raineri \& Rachlin, 1993). In other words, it takes relatively longer for the proportionate subjective value of larger rewards to decrease, compared to small rewards.

While previous work has documented the important practical consequences of individual differences in delay discounting, there is a paucity of data exploring in depth who is likely to actually engage in greater or less delay discounting. Studies that explored the relationship 
between age and delay discounting have found contradictory results (Green, Myerson, \& Ostaszewski, 1999; Harrison, Lau, \& Williams, 2002; Hirsh, Morisano, \& Peterson, 2008; Read \& Read, 2004; Reynolds et al., 2004).

Studies exploring personality and delay discounting have been limited to main effects and usually to certain traits (Becker et al., 2012; Daly, Harmon, \& Delaney, 2009; Ostaszewski, 1996). We take a holistic personality perspective to examine how individual differences in the Big Five personality traits are related to delay discounting overall, and, specifically, the magnitude of the reward. We focus on two core questions: (a) Are there personality differences in propensity to engage in delay discounting? (b) How do personality differences moderate the well-established 'magnitude effect'?

\section{Personality and Delay Discounting}

The dominant model used in personality research is the Five Factor Model (FFM; Costa \& McCrae, 1992; Goldberg, 1990). The 'Big Five' is composed of the traits (a) Openness to Experience (artistic versus conservative), (b) Conscientiousness (self-controlled versus easygoing), (c) Extraversion (outgoing versus reserved), (d) Agreeableness (compassionate versus antagonistic in thoughts and feelings), and (e) Neuroticism (emotionally unstable versus stable).

Our theoretical analysis suggests that several Big Five personality dimensions should be important in explaining individual differences in delay discounting. Specifically, steeper discounting rates are operationalized as an indicator of impulsivity (Bickel, Odum, \& Madden, 1999; Logue, 1988; Reynolds, 2006) - a construct that has become increasingly important in behavioral research. According to Depue and Collins (1999) "impulsivity comprises a heterogeneous cluster of lower-order traits that includes terms such as impulsivity, sensation 
seeking, risk-taking, novelty seeking, boldness, adventuresomeness, boredom susceptibility, unreliability, and unorderliness" (p. 495).

Impulsivity is conceptually related to four domains of the FFM. Costa and McCrae (1992) theorised that low self-control is measured by the impulsiveness and self-discipline facets, which are part of the Neuroticism and Conscientiousness domains, respectively. Impulsive individuals are said to be moody, irritable and excitable, while those low in selfdiscipline are lazy, disorganised and lacking meticulousness. The Conscientiousness domain also includes a deliberation facet. Individuals low on this facet are hasty, careless and impatient (Whiteside \& Lynam, 2001). The Extraversion domain includes an excitement seeking facet that is similar to venturesomeness (Eysenck \& Eysenck, 1977) or sensation seeking (Zuckerman, 1994). Individuals high in excitement seeking are pleasure-seeking, audacious and adventurous. Lastly, Soto and John (2009) identified Adventurousness as a facet under the domain of Openness to Experience. Individuals high in adventurousness have a preference for novel and intense experiences and have had unusual experiences. These characteristics are similar to the Excitement-seeking (Costa \& McCrae, 1992) or Gregariousness (Soto \& John, 2009) facet within the Extraversion domain. Thus, we developed four hypotheses:

1) Individuals high in Neuroticism will engage in steeper delay discounting.

2) Individuals low in Conscientiousness will engage in steeper delay discounting.

3) Individuals high in Extraversion will engage in steeper delay discounting (Hirsh, Morisano, \& Peterson, 2008; Reynolds et al., 2004).

4) Individuals high in Openness to Experience will engage in steeper delay discounting. Agreeableness is characterized by cooperation, empathy and consideration (Thompson, 2008). We did not see a strong theoretical reason to hypothesize a link between Agreeableness 
and delay discounting, although those low in Agreeableness may be likely to engage in steeper discounting due to their suspicious and skeptical nature. However, we viewed this last hypothesis as weak at best.

Past research addressing personality effects on delay discounting have identified important, yet inconsistent, roles played by Conscientiousness, Extraversion, and Neuroticism. Daly et al. (2009) and Dohmen et al. (2010) found contradictory evidence regarding correlations between Conscientiousness and delay discounting. Ostaszewski (1996) found a positive relationship between Extraversion and delay discounting, while Hirsh, Morisano \& Peterson (2008) identified interaction effects between both Neuroticism and Extraversion, and cognitive ability on delay discounting. However, these findings are limited in important ways. Much of delay discounting research has been conducted on relatively small $(\mathrm{n}<150)$ and homogenous student samples (Daly et al., 2009; Hirsh et al., 2010; Hirsh et al., 2008; Ostaszewski, 1996; Ostaszewski, 1997). Small samples result in poor statistical power, leading to high risk of erroneous findings and low generalizability. In studies with large samples, other methodological issues persisted, such as poor psychological measures of personality or delay discounting. For example, a study by Rustichini et al. (2012) compared the predictive power of measurements derived from decision theory and personality theory in a relatively large sample $(\mathrm{N}=1065)$ of American truck drivers. They used the Multidimensional Personality Questionnaire (Tellegen \& Waller, 1992) and mapped its scales on Big Five constructs - but, without empirical evidence of its validity. Further, studies conducted from an economic perspective often fail to be grounded in psychological theory or take a holistic personality approach. Thus, we took a psychological perspective in a large scale study to provide a more precise test of how personality can explain individual differences in delay discounting. 


\section{Personality as Moderating the 'Magnitude Effect' in Delay Discounting}

Previous work has documented the robustness of the 'magnitude effect' - people are comparatively more impatient for low value rewards than rewards of higher value. But whereas aggregate differences across groups are well established, nothing is known about individual differences in its strength - are some people less or more impatient for small versus large rewards? If so, people would respond differentially to delays of larger/smaller amounts - an important implication for real-life outcomes. For example, obesity represents a failure to wait for small rewards; perhaps it would show a better correlation with delay discounting of small rewards.

Established methods of calculating delay discounting (i.e. hyperbolic discounting; see Rachlin, Raineri, \& Cross, 1991; Takahashi, Ikeda, \& Hasegawa, 2007 for detailed description) account for the ratio between the immediate and delayed amount but not the magnitude of the delayed amount. Thus, our second aim was to examine how Big Five personality traits moderated the relationship between magnitude of the delayed amount and delay discounting. At present, no work has examined the role of personality in moderating the impact of amount on delay discounting. Studies do show that non-monetary rewards/consumables including food, drugs, access to video games etc. are discounted more steeply than money, even among the 'normal' population (Estle et al., 2007; Navarick, 1982; Odum, Baumann, \& Rimington, 2006; Petry, 2001)_possibly pointing to the role of other factors. There are also theoretical reasons to expect individual differences in size of the 'magnitude effect'. For instance, decision by sampling theory (Stewart, Chater, \& Brown, 2006) suggests that individuals change their subjective value of rewards according to values they're used to dealing with in everyday life. Personality may also explain individual differences in the 'magnitude effect', since it plays a 
pervasive role in our responses to daily life situations. However, given the dearth of empirical data about mechanisms behind the magnitude effect, we did not formulate specific hypotheses about how personality would moderate the effect of magnitude on delay discounting.

\section{Present Study}

Our study had two aims: First, to test specific hypotheses about how the Big Five personality traits explained individual differences in delay discounting; second, to test in an exploratory fashion the moderating role of personality on the 'magnitude effect'. In a large scale study $(N=5888)$, we assessed people's personalities and discounting behavior for variable amounts. Through such a large sample, we were able to detect even subtle effects of personality, offering the strongest test to date of the role of personality in delay discounting.

\section{Method}

\section{Participants and Procedure}

Data were collected via the 'myPersonality' application on Facebook (Stillwell \& Kosinski, 2011) between June 2010 and 2011. 9334 international users responded to a questionnaire called 'Today or Tomorrow' and the 100 item IPIP personality questionnaire (Goldberg et al., 2006). All measures were administered in English. From the pool of 9334 participants who completed the delay discounting measure, subsets of $N=5909$ for the main effects model and $N=5888$ for the interaction effects model were used in our analyses, based on the measures they had responded to. 58 participants were omitted from the final subset $(N=$ 5888 ) as they were outliers of 3 SDs above or below the delay discounting mean. It was not compulsory to answer all measures, and participants could opt out at any time by exiting the application. Of the participants who provided demographic details, 2468 were male (38\%) and 3987 were female (62\%), while average age was 23.64 years $(\mathrm{SD}=9.06)$ (see Appendix 1). 
Before starting, users selected the currency that they were most comfortable using from nine currencies (British Pound, Canadian Dollar, Euro, Filipino Peso, Indian Rupee, Indonesian Rupiah, Singapore Dollar, South African Rand, United States Dollar). Since the delayed amounts were based on previous research using US dollars, Google's exchange rate function (on $22^{\text {nd }}$ June 2010) was used to convert the monetary values to all nine currencies. Users were also told that they would not actually receive any monetary rewards at the end of the questionnaire ${ }^{1}$, and to assume no inflation when deciding on their responses.

\section{Delay Discounting Measure}

Seven sets of questions were presented in a randomized order to each participant. Participants were asked to repeatedly choose between two hypothetical monetary values various smaller amounts now compared to larger amounts at different points in the future. The amounts used as immediate rewards were $\$ 1000, \$ 950, \$ 900, \$ 850, \$ 750, \$ 600, \$ 500, \$ 400$, $\$ 250, \$ 150, \$ 100, \$ 60, \$ 20, \$ 10$, and $\$ 1$; while 1 week, 2 weeks, 1 month, 6 months, 1 year and 5 years were used as time delays. All these amounts and time delays were compared to $\$ 1000$ at the future time point. An additional set of questions asked participants to choose between immediate rewards with amounts one-tenth of those listed above (e.g. \$100, \$95) and a 1 month delay compared to $\$ 100$ at future time points. We calculated the level of delay discounting as parameter $k$ using established methods ${ }^{2}$ (i.e. hyperbolic discounting; see Rachlin, Raineri, \& Cross, 1991; Takahashi, Ikeda, \& Hasegawa, 2007 for a detailed description).

A hyperbolic function best explains delay discounting in humans because it accounts for time inconsistent discounting. This is the switch individuals make from future rewards to

\footnotetext{
${ }^{1}$ No significant effect of reward type was found in studies comparing hypothetical and real rewards (Johnson \& Bickel, 2002; Madden et al., 2004).

${ }^{2}$ Preliminary analyses showed that a hyperbolic, time inconsistent function fit the data better than an exponential, time consistent function.
} 
immediate rewards as the relative length of delay decreases (Rachlin, Raineri, \& Cross, 1991; Takahashi, Ikeda, \& Hasegawa, 2007). For example, people are likely to prefer $\$ 1000$ in 1 year and 1 day over $\$ 990$ in 1 year, but will prefer $\$ 990$ immediately rather than $\$ 1000$ tomorrow; short delays have a relatively greater impact than longer delays. The hyperbolic delay also fits individuals' discounting data better than the exponential function (Rachlin et al., 1991). The hyperbolic function uses the formula:

$$
V=A /(1+k D)
$$

Parameter $k$ refers to the individuals' estimate of delay discounting (i.e. steepness of the curve), $A$ the undiscounted reward amount, $D$ the length of delay, and $V$ the subjective discounted value of the reward.

The highest immediate and lowest delayed monetary values the participant selected were averaged to establish a point of inflection (Bickel et al., 1999; Stillwell \& Tunney, 2012) and then calculate parameter $(k)$. Further, $\log$ transformation (to the base 10) was used to normalize the data.

\section{Results}

\section{Data Analysis}

Appendix 1 provides sample demographics by currency used, while Appendix 2 provides descriptive statistics and correlations between trait-level (level 2) variables.

As traditional analysis of variance and multiple regression methods assume independence of observations, we used hierarchical linear modeling (HLM) techniques to take into account multiple observations from the same user (Raudenbush \& Bryk, 2002). The different delayed amounts (\$100 and \$1000) were considered interdependent (level 1) compared to personality factors and demographic variables that were measured only once (level 2). Using maximum- 
likelihood estimation, HLM yields independent estimates of the relationships among withinsubject variables (level 1) and models them between-subjects (at level 2) as a random effect (Snijders \& Bosker, 1999). Further, all continuous variables were centered (Aiken \& West, 1991) to minimize multicolinearity. The dependent variable, $\log (k)$ (i.e. rate of discounting), was calculated for each participant at delayed amounts of $\$ 100$ and $\$ 1000$. All data were analyzed using $R$ statistics with the lme4 package (Bates, Maechler, \& Bolker, 2012). P-values are not available within the lme4 package because there is continued debate about what the appropriate degrees of freedom are for a significance test in the multilevel context. However, t-values are provided. Given our large sample (main effects model: level $1 N=40,982$ and level $2 N=5909$; interaction effects: level $1 N=11,545$ and level $2 N=5,888$ ), we treat t-values which are greater than 2 as significant. Furthermore, we provide pseudo R-square as a measure of effect size and confidence intervals for all slopes at $+/-2.00 * \mathrm{SE}$ levels. It should be noted that moderate $\mathrm{t}$-scores (within $2.0-7.0$ approximately) will invariably have small effect sizes. The large sample size should be considered when interpreting statistical findings.

\section{Delay Discounting and Personality}

Our first goal was to test whether the Big Five personality traits predicted individual differences in delay discounting $(k)$. Thus, a hierarchical linear model was constructed as shown below (see Appendix 3a. for more details):

$\mathrm{DD}=\pi_{00}+\pi_{10} \mathrm{TIME}+\pi_{20} \mathrm{AMOUNT}+\pi_{01} \mathrm{OPENNESS}+\pi_{02}$ CONSCIENTIOUSNESS + $\pi_{03}$ EXTRAVERSION $+\pi_{04}$ AGREEABLENESS $+\pi_{05}$ NEUROTICISM $+\pi_{06} \mathrm{AGE}+$ $\pi_{07} \mathrm{GENDER}+\pi_{08-16} \mathrm{CURRENCY}+\mathrm{e}+\mathrm{u}_{0}$

In these analyses, we controlled for currency - to rule out purchasing power parity (PPP) as a covariate of delayed reward amount and length of delays - and age and gender to rule out 
important covariates of personality. However, the effects remained highly similar when these covariates were not included. All five personality traits were entered as simultaneous predictors to examine their unique effects.

As Table 1 shows, Openness, Conscientiousness, Extraversion, and Neuroticism significantly predicted delay discounting. Consistent with our prediction, individuals with greater Conscientiousness showed smaller k values_-representing less delay discounting. Similarly, individuals who were more extraverted and neurotic showed greater delay discounting. On the other hand, individuals higher in Openness to Experience engaged in less steep discounting; thus, disproving our hypothesis. Agreeableness was unrelated to delay discounting. These findings demonstrate that personality differences provide part of the answer to understanding how delay discounting rates vary between individuals.

The effect size estimates (see Table 1) for this model indicate that the magnitude of the delayed amount explains approximately $6 \%$ (pseudo R-square $=0.056$ ) of the variance in discounting rates within each individual. Individual personality factors explain between 0.3 and $1 \%$ of variance (pseudo R-square $=0.003-0.01$ ) in discounting behavior between individuals. It should be noted that moderate t-scores (within $2.0-7.0$ approximately) will invariably have small effect sizes. The large sample size should be considered when interpreting statistical findings.

\section{Moderating Role of Personality on the 'Magnitude Effect'}

Our second goal in the present paper was to examine whether Big Five personality traits moderated the 'magnitude effect'. The effect size estimates for the main effects model indicate that the magnitude of the delayed amount explains approximately $6 \%$ of variance in discounting rates within individuals, while personality factors explain approximately $1 \%$ of variance in 
discounting behavior between individuals. Considering this still leaves significant variance to be explained at the individual and group level, we investigated whether personality factors moderated the effect of delayed amount on discounting rates (cross-level interactions).

To test this hypothesis, we first tested whether our participants showed the "magnitude effect'. Consistent with past research, participants showed less delay discounting for larger amounts, $b=-0.15, \mathrm{CI}_{95}(-0.16,-0.14), \mathrm{t}=-20.51$. We next tested whether each of the Big Five personality dimensions moderated the effect of amount on delay discounting (see Table 2), such as (see Appendix 3b. for more details):

$\mathrm{DD}=\pi_{00}+\pi_{10}$ AMOUNT $+\pi_{01}$ PERSONALITY $+\pi_{11}$ AMOUNT $*$ PERSONALITY $+\pi_{02}$ AGE + $\pi_{03} \mathrm{GENDER}+\pi_{04} \mathrm{CURRENCY}+\mathrm{e}+\mathrm{u}_{0}$

In these analyses (see Table 2), we again controlled for currency, age and gender - and again, results were highly similar without these controls. In order to study the magnitude effect of delayed amounts, we compared the rate of discounting $(\log (k)$ values) with delayed amounts of $\$ 100$ and $\$ 1000$ at 1 month in the future. We found that Openness and Neuroticism dimensions significantly moderated the impact of amount. Specifically, people who are higher in Openness tend to discount $\$ 100$ less than those low in Openness, $b=-0.05, \mathrm{CI}_{95}(-0.08,-0.02), \mathrm{t}$ $=-2.95$; larger amounts magnify this effect by $60 \%$, with people higher in Openness discounting $\$ 1000$ far less, $b=-0.08, \mathrm{CI}_{95}(-0.11,-0.05), \mathrm{t}=-4.98$, than people low in Openness. In the opposite direction, individuals high in Neuroticism tend to discount $\$ 100, b=0.05, \mathrm{CI}_{95}(0.02$, 0.07), $\mathrm{t}=3.95$, more than individuals low in Neuroticism. Larger amounts also magnified this effect by $60 \%$, with highly neurotic people engaging in even greater discounting of $\$ 1000, b=$ 0.08, $\mathrm{CI}_{95}(0.05,0.10), \mathrm{t}=6.43$, than less neurotic people. Thus, for Openness and Neuroticism, 
greater amounts magnify people's personality tendency to engage in less (Openness) or more (Neuroticism) delay discounting.

\section{Discussion}

In this study, we took a personality perspective to understand who is more or less likely to engage in delay discounting. Partly in accordance with Daly et al. (2009), our findings indicate that Conscientiousness and Openness are both negatively related to delay discounting - people who are highly conscientious and/or highly open to experience tend to discount future rewards less than individuals who are low in either trait. In contrast, we found that Extraversion and Neuroticism positively predicted delay discounting, indicating that people who are highly extraverted and/or neurotic are less likely to wait for future rewards and more likely to go after immediate gains than individuals low in Extraversion and/or Neuroticism. Past research found similar relationships between Extraversion and discounting behavior (Hirsh et al., 2010;

Ostaszewski, 1996; Ostaszewski, 1997). Agreeableness, on the other hand, was unrelated to delay discounting - given our large sample, we can conclude there is likely an inappreciable relationship between Agreeableness and delay discounting in the general population. While some previous studies have looked at certain personality dimensions, studied small, homogenous samples, or used less robust measures of personality or delay discounting - we do so (a) in a large, diverse sample, (b) using robust psychometric measures and methodology and (c) model the direct effects of all Big Five personality dimensions simultaneously.

In addition to the above main effects, we also examined how Big Five personality traits interact with the well-established 'magnitude effect' - that is, people being more willing to wait for larger amounts, while showing steeper discounting for smaller amounts. Interestingly, we found that amount to be received in the future acted as a magnifier for the effects of Openness 
and Neuroticism. As discussed above, Openness predicted less delay discounting, whereas Neuroticism predicted more; however, these effects became even stronger when the delayed amount at stake was larger. People highly open to experiences are even more likely to wait for future gains if these gains are large as compared to people low in Openness to Experience. In stark juxtaposition, people high in Neuroticism were especially likely to not wait for larger gains as compared to their low Neuroticism counterparts. Thus, the relationship between Openness to Experience and Neuroticism to delay discounting is not simple; rather, it is highly dependent on the specific size of the reward one will receive in the future.

What might explain this pattern of results? As opposed to our initial hypotheses, individuals high in Openness in fact engage in less steep discounting than those low in Openness. An alternative explanation might be that impulsiveness makes one have insufficient patience to explore new ideas or concepts comprehensively; and, hence, less open to experience (Berlin \& Rolls, 2004). Further, Berlin and Rolls (2004) found that Openness to Experience negatively correlated with self-reported impulsivity. This questions whether Openness causes individuals to be impulsive or vice-versa.

Neuroticism, on the other hand, is characterized by emotional instability and impulsiveness. Costa and McCrae (1992) theorised that low self-control is measured by the impulsiveness facet of Neuroticism. Those high in Neuroticism may discount the future more because they have problems delaying gratification due to poor self-control (Hettema et al., 2006; Ostaszewski, 1996). This is magnified when the amounts are larger because the reward is likely to be perceived as far more enticing.

Our findings have several important implications for both the study of delay discounting and the interventions predicated on impulsivity and/or delay discounting principles (Chapman, 
Nelson, \& Hier, 1999; Swift \& Callahan, 2009). First, our results suggest that individual differences in certain aspects of personality determine variations in the discounting function for different delayed amounts. In accordance with recent findings, our findings imply different $k$ values at different delayed amounts, as opposed to one overall $k$ and delay discounting curve for each individual. The interaction between Openness and/or Neuroticism and size of reward suggests that certain personality traits may determine individual variation in the delay discounting curve. Thus, it appears that the discounting function is more complicated than simple [economic] decision making theories assume. Second, understanding the role of different personality dimensions in delay discounting can set the stage for the emergence of new intervention approaches. For example, the above findings can be used in rehabilitation of patients with Borderline Personality Disorder (BPD). Impulsivity is a key characteristic of BPD and research shows that it may be linked to deficits in time perception. Patients with BPD may be encouraged to be more deliberate in their actions - and are given verbal feedback on doing so as part of their rehabilitation (Berlin \& Rolls, 2004). Similarly, intervention methods aimed at reducing the lure of small rewards could focus on the Neuroticism trait, teaching individuals to control their emotions better. Preferring smaller immediate rewards over larger delayed rewards has various implications including failure to save for the future, credit card usage, health-related maladaptive behavior such as smoking and overeating.

Limitations to our study suggest certain future directions. One drawback of our study is that we did not have information on the socio-economic status of our participants and, thus, could not control for its potential effect. Future work should explain the role SES plays in delay discounting, and in particular, how it might affect the personality effects we have identified. Another limitation to our study is that we presented participants with only two different delayed 
amounts (\$100 and \$1000) and a single delay length. Further research could include a few more delayed amounts and/or time delays. Such a study should be conducted carefully as too many immediate and delayed amounts can confuse participants and cause them to mix-up immediate and delayed values.

Overall, the current study provides support for individual differences in the delay discounting curve. The findings highlight who are likely to engage in such behavior and the complexity of the dynamics with relation to the magnitude of the reward being discounted. Some individuals show more or less impulsivity/impatience for small delayed amounts than predicted by their discounting rate for larger delayed amounts. Personality partly explains the variation in delay discounting functions, implying that these differences are not merely the result of random noise, but rather a systematic variation related to stable personality traits. Openness and Neuroticism strongly moderated the relationship between delayed amounts and discounting rate. Based on these findings, there is scope for further research on the dynamics of discounting rates between various subsets of the population, such as substance abusers, gamblers and obese individuals. 


\section{References}

Aiken, L. S., \& West, S. G. (1991). Multiple regression: Testing and interpreting interactions. London: Sage.

Bates, D., Maechler, M., \& Bolker, B. (2012). lme4: Linear mixed-effects models using S4 classes (Version 0.999999-0): CRAN. Retrieved from http://cran.rproject.org/web/packages/lme4/index.html

Becker, A., Deckers, T., Dohmen, T., Falk, A., \& Kosse, F. (2012). The Relationship Between Economic Preferences and Psychological Personality Measures. Annual Review of Economics, Vol 4, 4, 453-+. doi: 10.1146/annurev-economics-080511-110922

Berlin, H. A., \& Rolls, E. T. (2004). Time perception, impulsivity, emotionality, and personality in self-harming borderline personality disorder patients. Journal of Personality Disorders, 18(4), 358-378. doi: 10.1521/pedi.2004.18.4.358

Bickel, W. K., Odum, A. L., \& Madden, G. J. (1999). Impulsivity and cigarette smoking: delay discounting in current, never, and ex-smokers. Psychopharmacology, 146(4), 447-454. doi: $10.1007 / p l 00005490$

Chapman, G. B., Nelson, R., \& Hier, D. B. (1999). Familiarity and time preferences: Decision making about treatments for migraine headaches and Crohn's disease. Journal of Experimental Psychology-Applied, 5(1), 17-34. doi: 10.1037//1076-898x.5.1.17

Costa, P. T., Jr., \& McCrae, R. R. (1992). Revised NEO Personality Inventory (NEO-PI-R) and NEO Five-Factor Inventory (NEO-FFI) manual. Odessa, Florida: Psychological Assessment Resources.

Costa, P. T., \& McCrae, R. R. (1992). NEO Personality Inventory professional manual. Odessa, Florida: Psychological Assessment Resources.

Daly, M., Harmon, C. P., \& Delaney, L. (2009). Psychological and biological foundations of time preference. Journal of the European Economic Association, 7(2-3), 659-669.

Depue, R. A., \& Collins, P. F. (1999). Neurobiology of the structure of personality: Dopamine, facilitation of incentive motivation, and Extraversion. Behavioral and Brain Sciences, 22(3), 491-569.

Dohmen, T., Falk, A., Huffman, D., \& Sunde, U. (2010). Are Risk Aversion and Impatience Related to Cognitive Ability? American Economic Review, 100(3), 1238-1260. doi: 10.1257/aer.100.3.1238

Estle, S. J., Green, L., Myerson, J., \& Holt, D. D. (2007). Discounting of monetary and directly consumable rewards. Psychological Science, 18(1), 58-63. doi: 10.1111/j.14679280.2007.01849.x

Eysenck, S. B. G., \& Eysenck, H. J. (1977). Place of impulsiveness in a dimensional system of personality description. British Journal of Social and Clinical Psychology, 16(FEB), 5768.

Goldberg, L. R. (1990). An alternative description of personality - The Big Five factor structure. Journal of Personality and Social Psychology, 59(6), 1216-1229. doi: 10.1037//00223514.59.6.1216

Goldberg, L. R., Johnson, J. A., Eber, H. W., Hogan, R., Ashton, M. C., Cloninger, C. R., \& Gough, H. G. (2006). The international personality item pool and the future of publicdomain personality measures. Journal of Research in Personality, 40(1), 84-96. doi: 10.1016/j.jrp.2005.08.007 
Green, L., Fry, A. F., \& Myerson, J. (1994). Discounting of delayed rewards: A life-span comparison. Psychological Science, 5(1), 33-36. doi: 10.1111/j.14679280.1994.tb00610.x

Green, L., Myerson, J., \& Ostaszewski, P. (1999). Discounting of delayed rewards across the life span: age differences in individual discounting functions. Behavioural Processes, 46(1), 89-96. doi: 10.1016/s0376-6357(99)00021-2

Harrison, G. W., Lau, M. I., \& Williams, M. B. (2002). Estimating individual discount rates in Denmark: A field experiment. American Economic Review, 92(5), 1606-1617. doi: 10.1257/000282802762024674

Hettema, J. M., Neale, M. C., Myers, J. M., Prescott, C. A., \& Kendler, K. S. (2006). A population-based twin study of the relationship between Neuroticism and internalizing disorders. American Journal of Psychiatry, 163(5), 857-864. doi: 10.1176/appi.ajp.163.5.857

Hirsh, J. B., Guindon, A., Morisano, D., \& Peterson, J. B. (2010). Positive Mood Effects on Delay Discounting. Emotion, 10(5), 717-721. doi: 10.1037/a0019466

Hirsh, J. B., Morisano, D., \& Peterson, J. B. (2008). Delay discounting: Interactions between personality and cognitive ability. Journal of Research in Personality, 42(6), 1646-1650. doi: 10.1016/j.jrp.2008.07.005

Johnson, M. W., \& Bickel, W. K. (2002). Within-subject comparison of real and hypothetical money rewards in delay discounting. Journal of the Experimental Analysis of Behavior, 77(2), 129-146. doi: 10.1901/jeab.2002.77-129

Kirby, K. N., \& Petry, N. M. (2004). Heroin and cocaine abusers have higher discount rates for delayed rewards than alcoholics or non-drug-using controls. Addiction, 99(4), 461-471. doi: 10.1111/j.1360-0443.2004.00669.x

Kirby, K. N., Petry, N. M., \& Bickel, W. K. (1999). Heroin addicts have higher discount rates for delayed rewards than non-drug-using controls. Journal of Experimental PsychologyGeneral, 128(1), 78-87. doi: 10.1037/0096-3445.128.1.78

Kirby, K. N., Winston, G. C., \& Santiesteban, M. (2005). Impatience and grades: Delay-discount rates correlate negatively with college GPA. Learning and Individual Differences, 51, 563-569.

Krishnan-Sarin, S., Reynolds, B., Duhig, A. M., Smith, A., Liss, T., McFetridge, A., . . Potenza, M. N. (2007). Behavioral impulsivity predicts treatment outcome in a smoking cessation program for adolescent smokers. Drug and Alcohol Dependence, 88(1), 79-82. doi: 10.1016/j.drugalcdep.2006.09.006

Lane, S. D., Cherek, D. R., Pietras, C. J., \& Tcheremissine, O. V. (2003). Measurement of delay discounting using trial-by-trial consequences Behavioural Processes, 64, 287-303.

Logue, A. W. (1988). Research on self-control - An integrating framework. Behavioral and Brain Sciences, 11(4), 665-678.

Madden, G. J., Raiff, B. R., Lagorio, C. H., Begotka, A. M., Mueller, A. M., Hehli, D. J., \& Wegener, A. A. (2004). Delay discounting of potentially real and hypothetical rewards: II. Between- and within-subject comparisons. Experimental and Clinical Psychopharmacology, 12(4), 251-261. doi: 10.1037/1064-1297.12.4.251

McCrae, R. R., \& Costa, P. T. (1987). Validation of the 5-factor model of personality across instruments and observers. Journal of Personality and Social Psychology, 52(1), 81-90. doi: 10.1037/0022-3514.52.1.81 
Mischel, W., Shoda, Y., \& Rodriguez, M. L. (1989). Delay of gratification in children. Science, 244(4907), 933-938. doi: 10.1126/science.2658056

Navarick, D. J. (1982). Negative reinforcement and choice in humans. Learning and Motivation, 13(3), 361-377. doi: 10.1016/0023-9690(82)90015-7

Odum, A. L. (2011). Delay discounting: Trait variable? Behavioural Processes, 87(1), 1-9. doi: 10.1016/j.beproc.2011.02.007

Odum, A. L., Baumann, A. A. L., \& Rimington, D. D. (2006). Discounting of delayed hypothetical money and food: Effects of amount. Behavioural Processes, 73(3), 278-284. doi: 10.1016/j.beproc.2006.06.008

Ostaszewski, P. (1996). The relation between temperament and rate of temporal discounting. European Journal of Personality, 10(3), 161-172.

Ostaszewski, P. (1997). Temperament and the discounting of delayed and probabilistic rewards: Conjoining European and American psychological traditions. European Psychologist, 2(1), 35-43.

Petry, N. M. (2001). Delay discounting of money and alcohol in actively using alcoholics, currently abstinent alcoholics, and controls. Psychopharmacology, 154(3), 243-250. doi: 10.1007/s002130000638

Rachlin, H., Raineri, A., \& Cross, D. (1991). Subjective-probability and delay. Journal of the Experimental Analysis of Behavior, 55(2), 233-244. doi: 10.1901/jeab.1991.55-233

Raudenbush, S. W., \& Bryk, A. S. (2002). Hierarchical Linear Models: Applications and Data Analysis Methods (2 ed.). Chicago: SAGE.

Read, D., \& Read, N. L. (2004). Time discounting over the lifespan. Organizational Behavior and Human Decision Processes, 94(1), 22-32. doi: 10.1016/j.obhdp.2004.01.002

Reynolds, B. (2006). A review of delay-discounting research with humans: relations to drug use and gambling. Behavioural Pharmacology, 17(8), 651-667. doi: 10.1097/FBP.0b013e3280115f99

Reynolds, B., Patak, M., Shroff, P., Penfold, R. B., Melanko, S., \& Duhig, A. M. (2007). Laboratory and self-report assessments of impulsive behavior in adolescent daily smokers and nonsmokers. Experimental and Clinical Psychopharmacology, 15(3), 264271. doi: 10.1037/1064-1297.15.3.264

Reynolds, B., Richards, J. B., Horn, K., \& Karraker, K. (2004). Delay discounting and probability discounting as related to cigarette smoking status in adults. Behavioural Processes, 65(1), 35-42. doi: 10.1016/s0376-6357(03)00109-8

Rustichini, A., DeYoung, C. G., Anderson, J., \& Burks, S. V. (2012). Toward the integration of personality theory and decision theory in the explanation of economic and health behavior Discussion Paper series.

Snijders, T., \& Bosker, R. (1999). Multilevel analysis: An introduction to basic and advanced multilevel modeling. London: Sage.

Soto, C. J., \& John, O. P. (2009). Using the California Psychological Inventory to assess the Big Five personality domains: A hierarchical approach. Journal of Research in Personality, 43(1), 25-38. doi: 10.1016/j.jrp.2008.10.005

Stewart, N., Chater, N., \& Brown, G. D. A. (2006). Decision by sampling. Cognitive Psychology, 53(1), 1-26. doi: 10.1016/j.cogpsych.2005.10.003

Stillwell, D. J., \& Kosinski, M. (2011). myPersonality Research Wiki. from http://mypersonality.org/wiki 
Stillwell, D. J., \& Tunney, R. J. (2012). Effects of measurement methods on the relationship between smoking and delay reward discounting. Addiction, 107(5), 1003-1012. doi: 10.1111/j.1360-0443.2011.03742.x

Swift, J. K., \& Callahan, J. L. (2009). A Delay Discounting Model of Psychotherapy Termination. International Journal of Behavioral Consultation and Therapy, 5(3), 278 293.

Takahashi, T., Ikeda, K., \& Hasegawa, T. (2007). A hyperbolic decay of subjective probability of obtaining delayed rewards. Behavioral and Brain Functions, 3. doi: 10.1186/1744-90813-52

Tellegen, A., \& Waller, N. G. (1992). Exploring personality through test construction:

Development of the Multi-dimensional Personality Questionnaire (MPQ). Department of Psychology. University of Minnesota.

Thompson, E. R. (2008). Development and validation of an International English Big-Five MiniMarkers. Personality and Individual Differences, 45(6), 542-548. doi: 10.1016/j.paid.2008.06.013

Weller, R. E., Cook, E. W., III, Avsar, K. B., \& Cox, J. E. (2008). Obese women show greater delay discounting than healthy-weight women. Appetite, 51(3), 563-569. doi: 10.1016/j.appet.2008.04.010

Whiteside, S. P., \& Lynam, D. R. (2001). The Five Factor Model and impulsivity: using a structural model of personality to understand impulsivity. Personality and Individual Differences, 30(4), 669-689. doi: 10.1016/s0191-8869(00)00064-7

Zuckerman, M. (1994). Behavioral expressions and biosocial bases of sensation seeking. New York: Cambridge University Press. 
Table 1 Main Personality Factors on Delay Discounting $(k)$

\begin{tabular}{|c|c|c|c|c|c|}
\hline \multirow{2}{*}{ Predictors } & \multirow[b]{2}{*}{$\boldsymbol{b}$} & \multirow[b]{2}{*}{$\mathbf{t}$} & \multicolumn{2}{|c|}{$\mathrm{CI}_{95}$} & \multirow[b]{2}{*}{ Pseudo R-square } \\
\hline & & & Lower & Upper & \\
\hline \multicolumn{6}{|l|}{ Level 1} \\
\hline Delayed amount & -0.292 & -45.45 & -0.304 & -0.279 & 0.056 \\
\hline Length of delay & -0.209 & -150.09 & -0.211 & -0.206 & 0.392 \\
\hline \multicolumn{6}{|l|}{ Level 2} \\
\hline Openness & -0.056 & -4.290 & -0.081 & -0.030 & 0.003 \\
\hline Conscientiousness & -0.070 & -6.690 & -0.095 & -0.045 & 0.008 \\
\hline Extraversion & 0.067 & 7.23 & 0.049 & 0.085 & 0.01 \\
\hline Agreeableness & -0.015 & -1.3 & -0.038 & 0.008 & 0.0001 \\
\hline Neuroticism & 0.070 & 7.06 & 0.051 & 0.090 & 0.009 \\
\hline Age & -0.001 & -1.05 & -0.002 & 0.001 & - \\
\hline Gender & 0.008 & 0.5 & -0.022 & 0.037 & - \\
\hline Currency - British Pound & 0.015 & 0.64 & -0.031 & 0.061 & - \\
\hline Currency - Canadian Dollar & -0.134 & -3.940 & -0.200 & -0.067 & - \\
\hline Currency - Euro & 0.023 & 0.86 & -0.030 & 0.077 & - \\
\hline Currency - Filipino Peso & 0.262 & 4.54 & 0.149 & 0.374 & - \\
\hline Currency - Indian Rupee & 0.201 & 3.17 & 0.077 & 0.325 & - \\
\hline Currency - Indonesian Rupiah & 0.422 & 4.33 & 0.231 & 0.613 & - \\
\hline Currency - Singapore Dollar & 0.103 & 1.96 & 0.000 & 0.206 & - \\
\hline Currency - South African Rand & -0.142 & -1.520 & -0.324 & 0.041 & - \\
\hline
\end{tabular}


Note. All numbers are unstandardized regression coefficients. The American dollar was used as the reference group when creating dummy variables for currency. Age, gender, length of delay and currency were entered into the model as control variables. 
Table 2 Interactions between Amount and Personality Factors on Delay Discounting $(k)$

\begin{tabular}{llllll}
\hline Predictors & b & t & & \multicolumn{2}{c}{ CI $_{95}$} \\
\cline { 3 - 5 } & & & Lower Upper
\end{tabular}

Level 1 predictors

Delayed amount

$-0.15 \quad-19.6 \quad-0.164 \quad-0.134$

Level 2 predictors

\begin{tabular}{ccccc} 
Openness & -0.05 & -2.95 & -0.078 & -0.016 \\
Conscientiousness & -0.08 & -5.85 & -0.1 & -0.05 \\
Extraversion & 0.066 & 5.79 & 0.044 & 0.088 \\
Agreeableness & -0.02 & -1.09 & -0.044 & 0.013 \\
Neuroticism & 0.048 & 3.95 & 0.024 & 0.072 \\
Age & -0 & -0.89 & -0.003 & 0.001 \\
Gender & -0.02 & -1.02 & -0.056 & 0.01 \\
Currency - British Pound & 0.027 & 1.056 & -0.024 & 0.078 \\
Currency - Canadian Dollar & -0.13 & -3.35 & -0.2 & -0.052 \\
Currency - Euro & 0.003 & 0.083 & -0.056 & 0.062 \\
Currency - Filipino Peso & 0.269 & 4.245 & 0.144 & 0.394 \\
$\begin{array}{c}\text { Currency - Indian Rupee } \\
\text { Currency - Indonesian Rupiah }\end{array}$ & 0.208 & 2.938 & 0.069 & 0.347 \\
Currency - Singapore Dollar & 0.411 & 3.841 & 0.201 & 0.621 \\
$\begin{array}{l}\text { Currency - South African Rand } \\
\text { C }\end{array}$ & -0.16 & 2.763 & 0.046 & 0.274 \\
\hline
\end{tabular}

Level $1 x$ level 2 interactions

Delayed amount x Openness $\quad-0.03 \quad-2.35 \quad-0.059 \quad-0.005$ 


$\begin{array}{ccccc}\text { Delayed amount x Conscientiousness } & 0.013 & 1.18 & -0.008 & 0.034 \\ \text { Delayed amount x Extraversion } & 0.012 & 1.28 & -0.007 & 0.032 \\ \text { Delayed amount x Agreeableness } & 0.016 & 1.3 & -0.008 & 0.04 \\ \text { Delayed amount x Neuroticism } & 0.03 & 2.92 & 0.01 & 0.05\end{array}$

Note. All numbers are unstandardized regression coefficients. The American dollar was used as the reference group when creating dummy variables for currency. Age, gender and currency were entered into the model as control variables. 
Figure 1 Delay discounting rates as a function of delayed amount and personality (1SD above/below the mean).
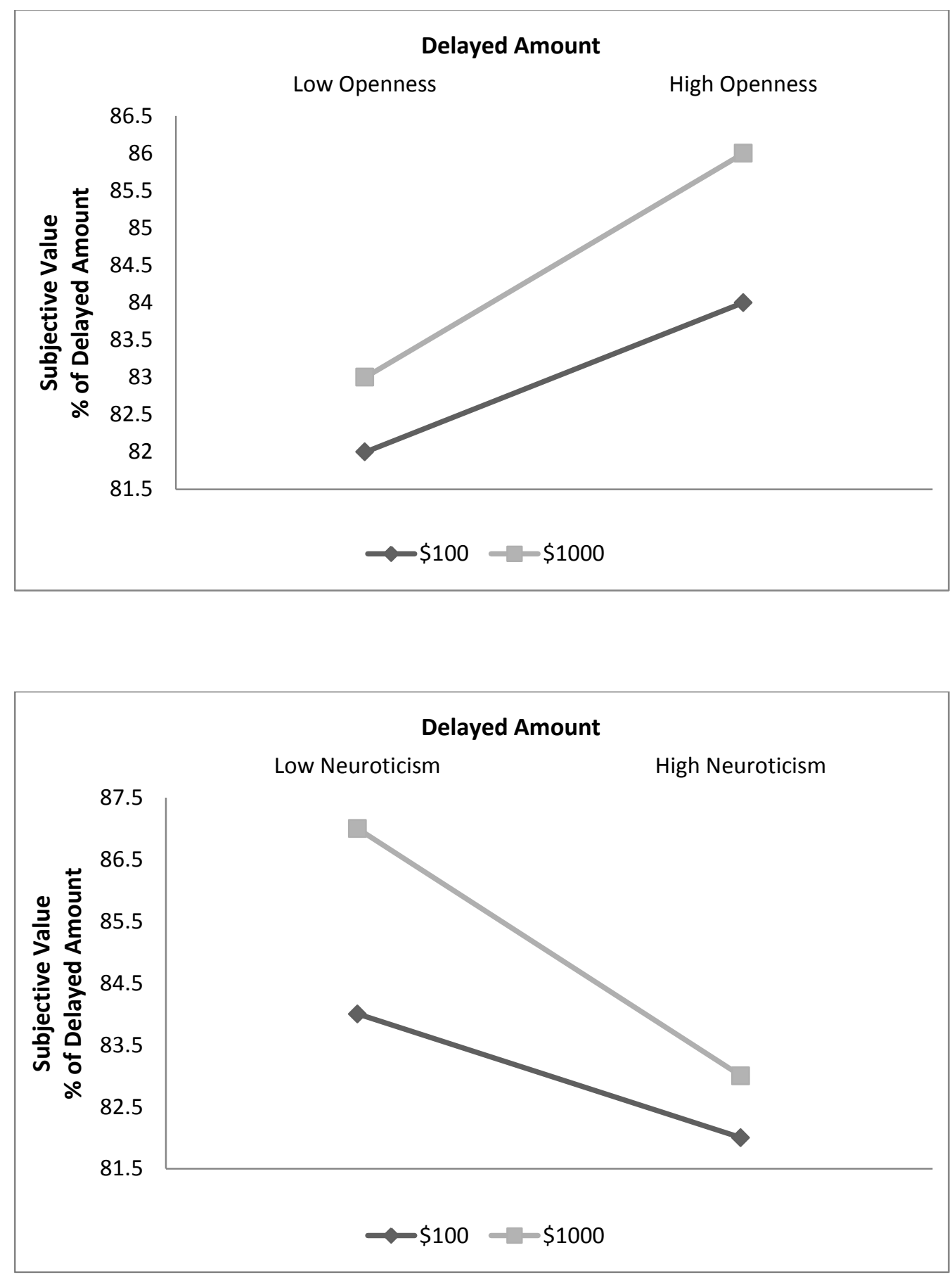


\section{Appendices}

Appendix 1 Sample demographics by currency used

\begin{tabular}{|c|c|c|c|c|}
\hline Currency & $\begin{array}{l}\text { Conversion } \\
\text { per } \$ 1 \text { USD }\end{array}$ & $N$ (Male/ Female) & Mean Age (SD) & $\begin{array}{c}\text { Mean } \log (k)^{*} \\
(\mathrm{SD})\end{array}$ \\
\hline British Pound & 0.68 & $959(262 / 408)$ & $25.24(10.02)$ & $-0.93(0.58)$ \\
\hline Canadian Dollar & 1.02 & $448(112 / 199)$ & $22.76(8.99)$ & $-1.08(0.59)$ \\
\hline Euro & 0.81 & $666(222 / 264)$ & $25.6(8.3)$ & $-0.97(0.57)$ \\
\hline Filipino Peso & 45.45 & $161(48 / 44)$ & $23.49(8.02)$ & $-0.73(0.59)$ \\
\hline Indian Rupee & 45.65 & $155(48 / 30)$ & $23.02(5.67)$ & $-0.75(0.57)$ \\
\hline Indonesian Rupiah & 9009 & $50(16 / 15)$ & $23.21(6.62)$ & $-0.55(0.64)$ \\
\hline Singapore Dollar & 1.38 & $186(52 / 67)$ & $19.99(5.46)$ & $-0.9(0.57)$ \\
\hline South African Rand & 7.51 & $64(14 / 26)$ & $26.61(8.89)$ & $-1.03(0.52)$ \\
\hline United States Dollar & 1 & $6645(1694 / 2934)$ & $23.34(9.08)$ & $-0.97(0.56)$ \\
\hline \multicolumn{5}{|c|}{ Note: Conversion per \$1 USD based on Google's exchange rate function on 22nd June 2010.} \\
\hline \multicolumn{5}{|c|}{ hyperbolic discounting curve). Larger values indicate steeper discounting. i.e. the subjective } \\
\hline value of a reward in th & ture decrea & immensely. Natura & transformat & as used to \\
\hline
\end{tabular}


Appendix 2 Correlations between all level 2 (between-individuals) variables

\begin{tabular}{|c|c|c|c|c|c|c|c|c|c|c|c|c|c|c|c|c|}
\hline & $\begin{array}{l}\text { Variables } \\
(\text { mean/SD })\end{array}$ & 1 & 2 & 3 & 4 & 5 & 6 & 7 & 8 & 9 & 10 & 11 & 12 & 13 & 14 & 15 \\
\hline 1 & $\begin{array}{c}\text { Openness } \\
(4.041 / 0.561)\end{array}$ & & & & & & & & & & & & & & & \\
\hline 2 & $\begin{array}{c}\text { Conscientiousness } \\
(3.328 / 0.721)\end{array}$ & -.035 & & & & & & & & & & & & & & \\
\hline 3 & $\begin{array}{l}\text { Extraversion } \\
(3.192 / 0.838)\end{array}$ & -.009 & & & & & & & & & & & & & & \\
\hline 4 & $\begin{array}{c}\text { Agreeableness } \\
(3.482 / 0.652)\end{array}$ & -.019 & .225 & .193 & & & & & & & & & & & & \\
\hline 5 & $\begin{array}{l}\text { Neuroticism } \\
(2.826 / 0.832)\end{array}$ & -.001 & .109 & .148 & .217 & & & & & & & & & & & \\
\hline 6 & $\begin{array}{c}\text { Age } \\
(2.359 / 0.909)\end{array}$ & .025 & -.069 & -.287 & -.342 & -.332 & & & & & & & & & & \\
\hline 7 & Gender & .034 & .023 & .206 & .060 & .088 & -.052 & & & & & & & & & \\
\hline 8 & British Pound & .012 & .016 & -.005 & .043 & .065 & .193 & .048 & & & & & & & & \\
\hline 9 & Canadian Dollar & .002 & -.072 & -.055 & .004 & .017 & .060 & .051 & -.004 & & & & & & & \\
\hline 10 & Euro & .015 & -.007 & -.028 & -.021 & -.019 & .010 & -.020 & .005 & -.074 & & & & & & \\
\hline 11 & Filipino Peso & -.011 & .066 & -.023 & -.001 & -.031 & -.029 & .062 & -.048 & -.096 & -.062 & & & & & \\
\hline
\end{tabular}




\begin{tabular}{lcccccccccccccccc}
12 & Indian Rupee & .007 & -.032 & .020 & .012 & -.017 & -.013 & -.002 & -.035 & -.042 & -.027 & -.035 & & \\
13 & Indonesian Rupiah & .008 & -.004 & .000 & .005 & -.017 & -.026 & -.004 & -.054 & -.038 & -.024 & -.032 & -.014 & \\
14 & Singapore Dollar & -.003 & -.026 & -.007 & -.008 & -.013 & -.003 & -.004 & -.022 & -.024 & -.016 & -.020 & -.009 & -.008 & \\
15 & South African Rand & -.013 & -.049 & -.022 & -.019 & -.040 & .017 & -.055 & -.021 & -.047 & -.030 & -.039 & -.017 & -.015 & -.010 & \\
16 & American Dollar & .015 & .011 & .017 & .013 & .001 & -.004 & .027 & .003 & -.026 & -.016 & -.021 & -.009 & -.008 & -.005 & -.010 \\
\hline
\end{tabular}

Note: Please refer to Table 1 for descriptive statistics by currency group 


\section{Appendix 3 Explanation of hierarchical linear models constructed during data analyses}

\section{3a. Main effects model}

$\mathrm{DD}=\pi_{00}+\pi_{10}$ TIME $+\pi_{20} \mathrm{AMOUNT}+\pi_{01} \mathrm{OPENNESS}+\pi_{02}$ CONSCIENTIOUSNESS + $\pi_{03}$ EXTRAVERSION $+\pi_{04}$ AGREEABLENESS $+\pi_{05}$ NEUROTICISM $+\pi_{06} \mathrm{AGE}+$ $\pi_{07} \mathrm{GENDER}+\pi_{08-16} \mathrm{CURRENCY}+\mathrm{e}+\mathrm{u}_{0}$

In this model, $\pi_{00}$ is the person's average delay discounting (DD) when all other factors equal zero. In the present study, both level 1 variables have the same average for all participants (since all participants received the same scenarios), and thus cannot explain any level 2 variance. Furthermore, level 2 variables in the model only account for between-subjects (level 2) variance. Thus, the level 2 control variables (age, gender and currency) in the model have no effect on the variance explained by AMOUNT and/or TIME.

$\pi_{20}$ AMOUNT refers to the difference in DD between delayed amounts of $\$ 100$ and $\$ 1000$, assuming other level 1 factors (i.e. $\pi_{10}$ TIME ) are average. $\pi_{10}$ TIME refers to the change in DD for 1 unit increase in TIME assuming AMOUNT = 0 (i.e. \$100). Since level 2 continuous variables - including personality factors and AGE - were grand-mean centered, $\pi_{01} \mathrm{OPENNESS}$ refers to the change in DD for 1 unit increase in OPENNESS, assuming all other level 2 variables are average. Similarly for $\pi_{02}$ CONSCIENTIOUSNESS, $\pi_{03}$ EXTRAVERSION, $\pi_{04}$ AGREEABLENESS, $\pi_{05}$ NEUROTICISM and $\pi_{06}$ AGE. $\pi_{07}$ GENDER is the difference in DD between men and women, assuming other level 2 factors are average. Similarly, for each of the currency groups $\left(\pi_{08-16} \mathrm{CURRENCY}\right)$. Finally, e refers to the residual error within-subjects, while $\mathrm{u}_{0}$ refers to the random effect between-subjects. 


\section{3b. Interaction effects model}

$\mathrm{DD}=\pi_{00}+\pi_{10}$ AMOUNT $+\pi_{01}$ PERSONALITY $+\pi_{11}$ AMOUNT $*$ PERSONALITY $+\pi_{02}$ AGE + $\pi_{03}$ GENDER $+\pi_{04}$ CURRENCY $+\mathrm{e}+\mathrm{u}_{0}$

Here, $\pi_{11}$ AMOUNT*PERSONALITY is the change in slope between PERSONALITY

(i.e. Big 5 traits) and DD for 1 unit increase in AMOUNT, or the change in slope between AMOUNT and DD for 1 unit increase in PERSONALITY (i.e. Big 5 traits). 